\title{
Nonnatural Reactivity of Cofactor-Dependent Enzymes upon Light Irradiation
}

Organo- and

Biocatalysis

\section{Key words}

ketoreductase

photoexcitation

nicotinamidedependent enzymes

debromination

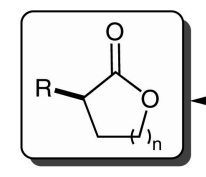

RasADH (1 mol\%)

GDH-105, glucose (200 mM) TRIS (pH = 7.0, $50 \mathrm{mM}, 10 \mathrm{mM} \mathrm{CaCl})$

10 examples up to $82 \%$ yield er up to $97: 3$
$\mathrm{NADP}^{+}(1 \mathrm{~mol} \%)$ glycerol, DMSO

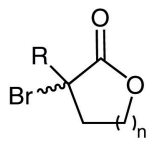

$460 \mathrm{~nm} \mathrm{hv}, 25^{\circ} \mathrm{C}, 12 \mathrm{~h}$
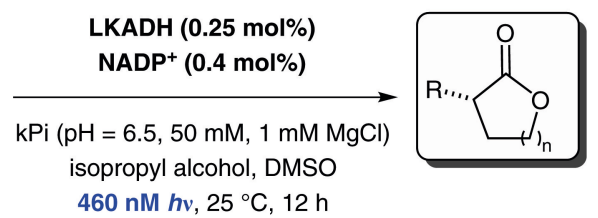

10 examples up to $91 \%$ yield er up to 2:98
Selected examples:<smiles>O=C1OCCCC1c1ccccc1</smiles>

RasADH: $51 \%$ yield $\mathrm{er}=92.5: 7.5$

LKADH: $81 \%$ yield er $=2: 98$<smiles>C=C1OCCCC1c1ccccc1C</smiles>

RasADH: $81 \%$ yield er $=81: 19$

LKADH: $80 \%$ yield er $=6: 94$<smiles>O=C1OCCCC1Cc1ccccc1</smiles>

RasADH: $29 \%$ yield er $=80: 20$

LKADH: $80 \%$ yield
$\mathrm{R}=\mathrm{Ar}, \mathrm{CH}_{2} \mathrm{Ar}$ $n=1,2$ lactones

Sy/facth the mom

Significance: An asymmetric light-mediated reductive debromination of racemic $\alpha$-bromolactones is reported by the Hyster group. The combination of a ketoreductase derived from either Lactobacillus kefiri (LKADH) or Ralstonia (RasA$\mathrm{DH}), \mathrm{NADP}^{+}$, and blue LED light furnished the desired lactones in high yields ( $\leq 91 \%)$ and good to excellent enantioselectivities (er $\leq 98: 2$ ).

SYNFACTS Contributors: Benjamin List, Grigory A. Shevchenko Synfacts 2017, 13(03), 0309 Published online: 15.02.2017 Dol: 10.1055/s-0036-1590002; Reg-No.: B00117SF
Comment: A great challenge in biocatalysis is the discovery and development of novel reaction pathways and catalytic functions. The authors demonstrate that a nicotinamide-dependent ketoreductase can change its natural function from carbonyl reduction to that of a radical initiator and chiral source of hydrogen, simply by irradiation of the cofactor with light. This strategy leads to novel and selective radical-mediated reactions. 